\title{
The complex chemical effects of COVID-19 shutdowns on air quality
}

\author{
Stay-at-home policies invoked in response to COVID-19 have led to well-publicized drops in some air pollutants. \\ The extent to which such reductions translate to improved air quality is dictated by not only emissions and \\ meteorology, but also chemical transformations in the atmosphere.
}

\author{
Jesse H. Kroll, Colette L. Heald, Christopher D. Cappa, Delphine K. Farmer, Juliane L. Fry, \\ Jennifer G. Murphy and Allison L. Steiner
}

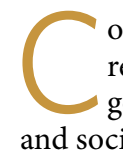

ompelling satellite images of reductions in air pollutants as governments enforced quarantine and social-distancing policies have sparked suggestions that the COVID-19 pandemic has led to cleaner air. This has propelled efforts to measure and analyse changes to air quality (defined here as the abundance of gases and particles harmful to human health), and a rush to publish scientific studies characterizing the links between the pandemic and air pollution (for example, refs. ${ }^{1-4}$; for an updated list of papers, see https://go.nature.com/covid19airpollution). Much of this discussion, both in the media and in the scientific literature, has neglected the central role of chemical reactions and transformations in dictating air quality, or has suggested that the role of this chemistry is unexpected. However, atmospheric chemical reactions are essential links between emissions and atmospheric composition. Because these linkages can be highly nonlinear, atmospheric chemistry complicates how pandemic-induced emission changes have and will continue to impact air quality; overlooking this chemistry undermines public understanding of air pollution, and risks erroneous decision-making.

\section{Air pollution: more than just $\mathrm{NO}_{x}$ emissions}

The COVID-19 pandemic has undoubtedly altered emissions, as, for example, people spend more time in their homes and less time in transit ${ }^{5}$. Less travel (passenger vehicles, public transit, aircrafts) reduces emissions of nitrogen oxides $\left(\mathrm{NO}_{x}=\mathrm{NO}\right.$ $+\mathrm{NO}_{2}$ ), a major combustion by-product. Pervasive declines in atmospheric $\mathrm{NO}_{2}$ (a pollutant associated with adverse respiratory effects) through the spring of 2020 exemplify the effect of these lowered emissions. $\mathrm{NO}_{2}$ is concentrated in urban regions (due to vehicle emissions and a short chemical lifetime) and is easily

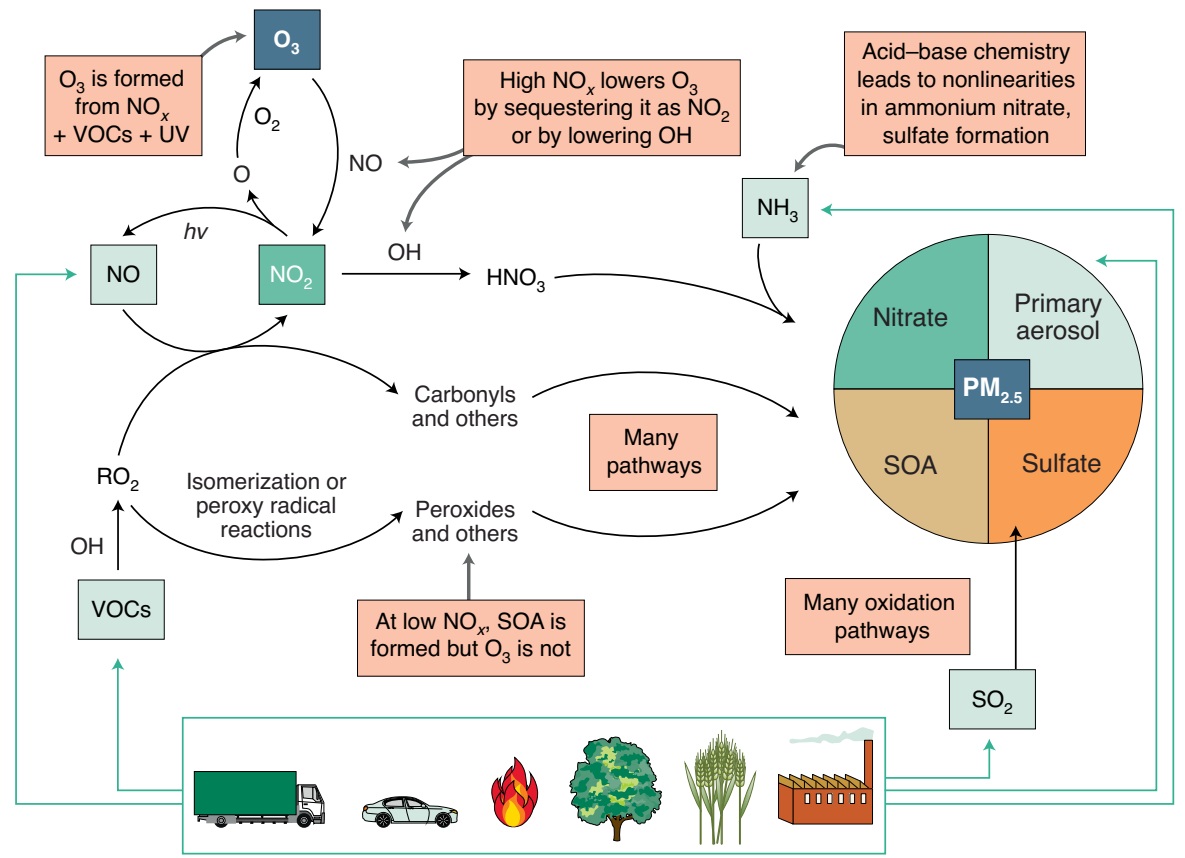

Fig. 1 | Simplified overview of the atmospheric chemistry of ozone and $\mathbf{P M}_{2.5}$ formation. The orange boxes highlight key complexities, nonlinearities and uncertainties. Primary emissions are denoted by green arrows; secondary chemical reactions are denoted by black arrows.

observed from space, thus, satellite images have provided clear evidence of declines in populated regions in recent months, spurring commentary on improving air quality $^{1,2}$. Reductions have been particularly stark in regions dominated by diesel vehicles, which are higher $\mathrm{NO}_{x}$ emitters than their gasoline counterparts ${ }^{6}$. While the ease with which satellite images of $\mathrm{NO}_{2}$ are generated has led many to focus on $\mathrm{NO}_{x}$ emissions changes, attributing this decline to COVID-19 is complicated by a number of factors. For example, meteorology and emissions are seasonally variant, generally leading to a decline in $\mathrm{NO}_{2}$ from winter to spring in the Northern Hemisphere ${ }^{7}$. Furthermore, air quality regulations in North America, Europe and, more recently, China, and resulting reductions of emissions are responsible for long-term declines in $\mathrm{NO}_{\mathrm{x}}$ (for example, refs. ${ }^{8,9}$ ). As a result, in many regions of the world $\mathrm{NO}_{2}$ is no longer a pollutant of leading concern; for example, in 2019 the whole of the United States complied with the air quality standards for $\mathrm{NO}_{2}$ (https://www.epa.gov/ air-trends/air-quality-national-summary). Thus, any COVID-19-driven decline must be disentangled from this pre-existing trajectory, as well as from meteorologically driven variability (for example, refs. ${ }^{10,11}$.

While the decline in $\mathrm{NO}_{2}$ undoubtedly mitigates its associated health burden, it is merely one air pollutant of many; human 
activities emit a wide range of gases and particles into the atmosphere. Though emissions from passenger vehicles and aviation have undeniably dropped during the pandemic, emissions from other sectors (for example, power generation, agriculture) are largely unaffected by COVID-19, as of course are emissions from natural sources (for example, plants, wildfires, dust, volcanoes). Thus, the emissions of pollutants other than $\mathrm{NO}_{x}$ - such as sulfur dioxide $\left(\mathrm{SO}_{2}\right)$, ammonia $\left(\mathrm{NH}_{3}\right)$, and various volatile organic compounds (VOCs) - are likely to exhibit changes that are quite different from what has been observed for $\mathrm{NO}_{2}$, and these differences are likely to vary from location to location. We might even anticipate an increase in certain emissions, for example of volatile chemical products ${ }^{12}$ from increased household and workplace cleaning.

Moreover, these direct emissions are considered 'primary pollutants', whereas the preponderance of pollutants that are deleterious to human health are 'secondary' - that is, resulting from chemical processing in the atmosphere. These include ozone $\left(\mathrm{O}_{3}\right)$, and the majority of $\mathrm{PM}_{2.5}$ (particulate matter less than $2.5 \mu \mathrm{m}$ in diameter), the leading air pollutants of concern for human health - exposure to it has been estimated to be responsible for over eight million premature deaths per year ${ }^{13}$. Therefore, to fully assess the global air quality consequences of COVID-19, we must investigate the impact that changes in primary pollutant emissions have on these secondary chemical reactions.

\section{Atmospheric chemical reactions and secondary pollutants}

The role of atmospheric chemical reactions in the formation of air pollutants was first identified in the early 1950s by Haagen-Smit ${ }^{14,15}$. In a series of laboratory experiments aimed at reproducing 'Los Angeles smog', it was shown that the noxious components included ozone and aerosol particles, formed when a mix of VOCs and $\mathrm{NO}_{x}$ (both of which are emitted from vehicles, as well as other sources) are exposed to sunlight.

In the decades since, atmospheric chemists have worked to unravel the underlying chemistry of ozone and aerosol formation, both in polluted urban regions where they are harmful to human health, and in the global atmosphere where they impact climate. Figure 1 shows an overview of our understanding of this chemistry. Atmospheric photooxidation is initiated by a handful of strong oxidants - most importantly the hydroxyl radical, $\mathrm{OH}-$ that can react with a wide range of species emitted into the atmosphere. This includes inorganic species (for example, $\mathrm{NO}_{\mathrm{x}}, \mathrm{SO}_{2}$, $\mathrm{CO})$ as well as organic ones, emitted into the atmosphere from both anthropogenic and natural sources. The products and by-products of these oxidation reactions depend not only on the compound being oxidized, but also on the concentrations of other species that may affect this oxidation chemistry. Most important in this regard is $\mathrm{NO}_{x}$, which controls the fate of peroxy radical intermediates $\left(\mathrm{HO}_{2}\right.$ and $\left.\mathrm{RO}_{2}\right)$ formed as intermediates in the oxidation of volatile organic compounds and other species.

Under relatively 'clean' (low-NO) conditions, peroxy radicals will react with other peroxy radicals, or (in the case of $\mathrm{RO}_{2}$ ) will isomerize; under polluted urban conditions they react with $\mathrm{NO}$, forming $\mathrm{NO}_{2}$, which rapidly photolyzes in daytime to produce ozone.

The dependence of ozone production on the concentrations of VOCs and $\mathrm{NO}_{x}$ is complex and nonlinear. Under conditions in which VOC levels are high but $\mathrm{NO}_{x}$ levels are low, the chemistry is ' $\mathrm{NO}_{x}$ limited', and more $\mathrm{NO}_{x}$ means more ozone. But at higher $\mathrm{NO}_{x}$, the case in many polluted cities worldwide, the system can become ' $\mathrm{NO}_{x}$ saturated', and more $\mathrm{NO}_{x}$ does not generate more ozone. In fact, the opposite occurs: the additional $\mathrm{NO}_{x}$ serves as a sink for $\mathrm{OH}$ radicals, slowing down the oxidation of VOCs oxidation and suppressing ozone production. Moreover, $\mathrm{NO}_{x}$ can sequester $\mathrm{O}_{3}$ in temporary reservoirs such as $\mathrm{NO}_{2}$ and $\mathrm{N}_{2} \mathrm{O}_{5}$. This chemistry has important implications for the relationship between emissions and air quality because, under these conditions, lower $\mathrm{NO}_{x}$ emissions can actually lead to higher ozone levels. This causes the well-documented 'weekend effect', with ozone going up on weekends due to lower $\mathrm{NO}_{x}$ levels from reduced traffic. Thus, the observation during the pandemic that ozone in polluted cities is not dropping as fast as other pollutants - or is even increasing - is unsurprising, because it is a direct consequence of chemistry known since at least the late $1980 \mathrm{~s}^{16,17}$. But the magnitude (and even sign) of the change in ozone at a given location is not obvious, as it depends critically on a number of local factors other than $\mathrm{NO}_{x}$ level, such as the amount and reactivity of the VOCs, oxidant levels, as well as meteorology; understanding how these conditions regulate the response of ozone to emission changes is central to interpreting COVID-19's impact on air quality.

The chemistry of particulate matter formation is even more complex and challenging to disentangle. Some fraction of $\mathrm{PM}_{2.5}$ is primary, emitted directly from combustion and other sources; when such particles dominate, changes to primary particulate matter may dominate the air quality response to COVID-19. However, in much of the world, $\mathrm{PM}_{2.5}$ is largely secondary in nature, produced when gas-phase species react to form products of low enough volatility to condense into the particle phase. Key classes of secondary particulate matter include sulfates (formed from $\mathrm{SO}_{2}$ oxidation), nitrates (formed from $\mathrm{NO}_{2}$ oxidation), and secondary organic aerosol (SOA, formed from VOC oxidation). $\mathrm{PM}_{2.5}$ levels are thus a strong function of the emissions of these precursors, which again are each affected differently by COVID-19 policies. The chemical transformations of each add additional complexity, and are currently the subject of intense study. The oxidation of $\mathrm{SO}_{2}$ to $\mathrm{H}_{2} \mathrm{SO}_{4}$ can occur via a number of pathways, which are still being elucidated ${ }^{18}$. The oxidation of $\mathrm{NO}_{2}$ to form $\mathrm{HNO}_{3}$ is well understood, but nitrate partitioning to the particle phase is driven by acid-base chemistry typically involving $\mathrm{NH}_{3}$, and so depends on factors such as temperature, relative humidity, $\mathrm{NH}_{3}$ levels, and particle $\mathrm{pH}^{19,20}$. The formation of SOA is more complex still, being formed from scores of precursor VOCs, with each reacting via numerous pathways to form a complex mixture of hundreds or thousands of reaction products ${ }^{21}$. Thus, SOA formation is strongly dependent on the ambient VOC mixture, as well as on reaction conditions. Both are likely to have been affected during the pandemic. For example, reductions in $\mathrm{NO}_{x}$ may lead to increased production of SOA, potentially offsetting changes resulting from decreased VOC emissions ${ }^{22}$; however, changes in oxidant levels also need to be taken into account ${ }^{23}$. Changes in chemical regime may also affect the volatility of the products of VOC oxidation, potentially altering the prevalence of new particle formation ${ }^{24}$. Finally, all of these secondary $\mathrm{PM}_{2.5}$ components - nitrate, sulfate, and organics - can interact and undergo further reactions in the condensed phase, altering its volatility and atmospheric lifetime in ways that depend on the detailed composition. Because of the chemical complexity of the system, these dependencies are nonlinear and uncertain, and are a major focus of modern atmospheric chemistry.

\section{Opportunities for improved atmospheric chemical understanding}

Decreases in emissions of air pollutants are critical for achieving improved air quality worldwide. However, because of the above interdependencies and nonlinearities in chemistry - many of which remain poorly understood - the response of secondary pollutants (namely $\mathrm{O}_{3}$ and $\mathrm{PM}_{2.5}$ ) to 
COVID-19-induced emission changes is complex and uncertain. While reports of concentration changes for a small handful of pollutants may be a first step in improving our understanding of these linkages, they in themselves provide little insight into this chemistry and its consequent effects on air quality.

At the same time, analyses of the changes in atmospheric composition over the last few months, and in the months to come with easing (and possible retightening) of COVID-19-based restrictions, will provide new insight into the detailed chemistry linking emissions and secondary air pollution ${ }^{4,25,26}$. Such analyses will also inform what policy interventions might be most efficient for improving future air quality. They are, however, not trivial, since it can be extremely challenging to derive process-level understanding and establish causation from concentration measurements. In the past, such challenges have been addressed by examining responses of secondary pollutants to changes in conditions and emissions; examples include the weekday-weekend effect, temperature-driven variability, and the decades-long decline in emissions due to various control policies. The COVID-induced changes in anthropogenic emissions add a powerful new lens for such analyses, since the magnitude and rate of the present changes are arguably the largest ever seen in modern atmospheric chemistry.

Given the complexity of the atmospheric chemical system, new insight into the reactions governing secondary pollutant formation will require data not just from routine air quality and satellite measurements, but also from advanced research-grade instrumentation, to provide measurements of individual organic species and particulate matter composition. State-of-the-art chemical-transport models will also be needed to evaluate the consistency of these measurements with our understanding. Such studies will provide new information on several fundamental components of the atmospheric chemical system:

- Key emissions What is the influence of specific chemical compounds or classes on local $\mathrm{O}_{3}$ and $\mathrm{PM}_{2.5}$ formation?
What do the effects of differential changes to key precursor species (VOCs/ $\mathrm{NO}_{x}$ in the case of $\mathrm{O}_{3}, \mathrm{SO}_{2} / \mathrm{NO}_{x} / \mathrm{NH}_{3} / \mathrm{VOCs}$ in the case of particulate matter) tell us about the underlying chemistry?

- Chemical regime How do changes in emissions influence oxidant levels, peroxy radicals $\left(\mathrm{RO}_{2}\right.$ and $\left.\mathrm{HO}_{2}\right)$, and local chemical regimes (for example, $\mathrm{NO}_{x}$-limited versus $\mathrm{NO}_{x}$-saturated conditions)? What effect do these have on secondary pollutants?

- $\quad \mathbf{P M}_{2.5}$ chemistry and impacts How have number concentrations, mass concentrations, and chemical composition of particulate matter changed? Do such changes have an impact on the toxicity or cloud-forming potential of the particles?

- Global atmosphere Are changes to atmospheric composition limited to urban/polluted regions, or do they extend to remote/pristine ones as well?

Such studies, especially when carried out in multiple regions across the globe, can serve to directly inform the development of future air quality policies. In particular, the rapid and large changes to pollutant emissions (owing to COVID-19-related changes) provide a glimpse into a future of intentionally lowered emissions. An improved understanding of how emissions from specific sectors - such as passenger vehicles, air traffic, industry, and so on - influence the formation of secondary pollutants will provide insight into which potential interventions - such as vehicle electrification and electricity grid decarbonization - will be most effective at mitigating air pollution and climate change in the future.

The COVID-19 perturbation to air quality is on-going and dynamic, as regions undergo tightening and loosening of restrictions on human mobility. In the fullness of time, careful analysis of the resulting changes to emissions and atmospheric composition may yield vital new insights into how chemistry controls air quality, on both local and global scales.
Juliane L. Fry ${ }^{4}$, Jennifer G. Murphy ${ }^{5}$ and Allison L. Steiner

${ }^{1}$ Department of Civil and Environmental Engineering, MIT, Cambridge, MA, USA. ${ }^{2}$ Department of Civil and Environmental Engineering, University of California, Davis, CA, USA. ${ }^{3}$ Department of Chemistry, Colorado State University, Fort Collins, CO, USA. ${ }^{4}$ Department of Chemistry, Reed College, Portland, OR, USA. ${ }^{5}$ Department of Chemistry, University of Toronto, Toronto, Ontario, Canada. ${ }^{6}$ Department of Climate and Space Sciences and Engineering, University of Michigan, Ann Arbor, MI, USA. ${ }^{7}$ Twitter: @jesse_ kroll@coletteheald@CappaSnappa@ChemDelphine @envchemjen@julianefry@alsteine

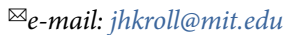

Published online: 25 August 2020

https://doi.org/10.1038/s41557-020-0535-z

References

1. Bauwens, M. et al. Geophys. Res. Lett. 47, e2020GL087978 (2020).

Liu, F. et al. Science Advances 6, eabc2992 (2020).

3. Shi, X. \& Brasseur, G. P. Geophys. Res. Lett. 47, e2020GL088070 (2020).

4. Le, T. et al. Science 369, 702-706 (2020).

5. Quéré, L. et al. Nat. Clim. Chang. 8, 647-653 (2020).

6. Weiss, M., Bonnel, P., Hummel, R., Provenza, A. \& Manfredi, U. Environ. Sci. Technol. 45, 8575-8581 (2011).

7. Martin, R. V. et al. J. Geophys. Res. 108, 4537 (2003).

8. Schneider, P. \& van der, A. R. J. J. Geophys. Res. 117, D16309 (2012).

9. Krotkov, N. A. et al. Atmos. Chem. Phys. 16, 4605-4629 (2016).

10. Li, K. et al. Proc. Natl Acad. Sci. 116, 422-427 (2019).

11. Vu, V. T. et al. Atmos. Chem. Phys 19, 11303-11314 (2019).

12. McDonald, B. C. et al. Science 359, 760-764 (2018).

3. Burnett, R. et al. Proc. Natl Acad. Sci. USA. 115 9592-9597 (2018)

14. Haagen-Smit, A. J. Ind. Eng. Chem. 44, 1342-1346 (1952).

15. Haagen-Smit, A. J., Bradley, C. \& Fox, M. Ind. Eng. Chem. 45, 2086-2089 (1953)

16. Chameides, W. L., Lindsay, R. W., Richardson, J. \& Kiang, C. S. Science 241, 1473-1475 (1988).

7. Trainer, M. et al. Nature 329, 705-707 (1987).

18. Wang, J. et al. Nat. Commun. 11, 2844 (2020).

19. Murphy, J. et al. Faraday Discuss. 200, 379-395 (2017).

20. Guo, H. et al. Atmos. Chem. Phys. 18, 12241-12256 (2018).

21. Goldstein, A. H. \& Galbally, I. E. Environ. Sci. Technol. 41 1514-1521 (2007).

22. Xu, L. et al. Proc. Natl Acad. Sci. USA 112, E4506-E4507 (2015).

23. Pye, H. O. T. et al. Proc. Natl Acad. Sci. USA 116, 6641-6646 (2019).

24. Lehtipalo, K. et al. Sci. Adv. 4, eaau5363 (2018).

25. Sicard, P. et al. Sci. Total Environ. 735, 139542 (2020).

26. Zheng, H. et al. Sci. Total Environ. 739, 140000 (2020).

Acknowledgements

We acknowledge Pallavi Pant for curating the list of COVID-19 papers relevant to air pollution mentioned in the first paragraph.

Competing interests

The authors declare no competing interests. 